\title{
Toxicological Pattern of Poisoning in Urban Hospitals of Western India
}

\author{
Raut Asawari', Pawar Atmaram', Kakane Bhagwan², Dave Priti ${ }^{3}$, Shaj Kavya ${ }^{4}$, Gulam Ali Jabeen ${ }^{4}$ \\ 'Department of Clinical Pharmacy, Poona College of Pharmacy, Bharati Vidyapeeth University, Pune, Maharashtra, INDIA. \\ ${ }^{2}$ Additional Civil Surgeon, District Hospital, Aundh, Pune, Maharashtra, INDIA. \\ 3Department of General Medicine, Bharati Medical College, Bharati Vidyapeeth University, Pune, Maharashtra, INDIA. \\ ${ }^{4}$ Department of Clinical Pharmacy, Doctor of Pharmacy, Poona College of Pharmacy, Bharati Vidyapeeth University, Pune, Maharashtra, INDIA.
}

\begin{abstract}
Background: Poisoning is a significant global public health problem which leads to nearly a million deaths each year. Incidence of poisoning in India is among the highest in the world. Despite the vast number, evidence on prevalence pattern in India is yet limited. Objective: The present study aimed to characterise acute poisoning cases with respect to the demographics, effect due to time lag and treatment outcomes. Methods: The cross sectional retrospective study was conducted from January 2013 to December 2015 in government and private teaching hospitals. Results: Of all reviewed cases male over female predominance was observed. Maximum poisoning was observed in the age group 20-35 years with an increased incidence of female cases in age category 13-19 years. Household and agricultural agents (56.4\%) were associated with most poisoning. Intentional poisoning was more common (53.3\%) and predominant in age category 20-35 years. Maximal exposure was observed between 6 pm $12 \mathrm{am}$. Maximum patients $(77.6 \%)$ responded to the therapy given while $12.6 \%$ absconded, took discharge against medical advice or were referred to another hospital. The mortality rate was $9.6 \%$ with male predominance. Conclusion: The study concludes that the burden of poisoning demands
\end{abstract}

strategies for prevention, identification and rational management providing optimal treatment outcomes.

Key words: Poisoning pattern, Acute poisoning, Time lag, Treatment outcomes, Mortality.

Key message: Epidemiological study on prevalence of Poisoning and its outcomes in different regions of India are less documented. Such studies help in developing poison registries and development of hospital based poison information centres.

\section{Correspondence :}

Asawari Raut, Poona College of Pharmacy, Bharati Vidyapeeth University, Erandwane, Pune, Maharashtra, INDIA.

Phone: $91+9960821040$

Email: pharmasawari1@gmail.com

DOI: 10.5530/jyp.2017.9.63

\section{INTRODUCTION}

Poisoning is a significant global public health problem ranking $45^{\text {th }}$ in total death worldwide. Nearly a million people die each year because of suicide, and it is estimated that deliberate ingestion of pesticides causes $3,70,000$ deaths each year. According to WHO data, in 2012 an estimated $1,93,460$ people died worldwide from unintentional poisoning. Of these deaths, $84 \%$ occurred in low- and middle-income countries. In the same year, unintentional poisoning caused the loss of over 10.7 million years of healthy life. ${ }^{1}$

The incidence of poisoning in India is among the highest in the world. It is estimated that more than 50,000 people die every year from toxic exposure. According to the National Poisons Information Centre, New Delhi, analysis of poisoning calls showed that the highest incidence of poisoning was due to household agents (44.1\%) followed by drugs (18.8\%), agricultural pesticides (12.8\%), industrial chemicals $(8.9 \%)$, animals bites and stings (4.7\%), plants (1.7\%), unknown $(2.9 \%)$ and miscellaneous groups (5.6\%). The commonest cause of poisoning in developing countries is pesticides which includes organophosphates, carbamates, chlorinated hydrocarbons, pyrethroids and aluminium or zinc phosphide. The reason behind this upsurge is the agriculture based economics, poverty, unsafe practices, illiteracy, ignorance and easy availability of highly toxic pesticides. Majority of victims of poisoning are from lower socio economic status. ${ }^{2}$

Globally much is known and documented on poisoning. On the contrary, lack of updated information due to unavailability of published data

and accessible databases, a few established poison centres and national surveillance is faced in India. Similar challenges have been observed in other countries such as China, Botswana and South Africa. This paucity of information on risk population, circumstances and toxic substances is a hurdle to effective poisoning prevention and targeted intervention programs. Therefore, the need for a current review of poisoning patterns in India is imperative. This study sought to characterize poisoning with regard to demographic factors (i.e. age, sex and residence), common toxic agents used and their case fatality rates as well as the overall mortality rate of acute poisoning in Pune district.

Pune is a district in the state of Maharashtra in India. According to the most recent census in 2011, the total population was 9.4 million making it the $4^{\text {th }}$ most populous district in India. The city accommodates many industrial areas which provides easy accessibility of large number of chemicals and pesticides which in turn results in tremendous use of these agents for poisoning. The agricultural diversity of Pune has resulted in increase of animal bites and stings and also use of pesticides for deliberate self harm and accidental exposures.

\section{METHODOLOGY}

\section{Study Area}

The study was conducted in Pune district of Maharashtra, which resides a total population of 9.4 million inhabitants with a male to female ratio 
of 1.1:1. It forms a part of the topical monsoon land and therefore shows a significant seasonal variation in temperature and rainfall.

The Pune city resides many multispecialty hospitals. The Government hospital, a 380 bedded multispecialty hospital, is located in Pimpri Chinchwad which engulfs a wide area of surrounding suburban and industrial areas like Aundh, Bhosri, Nigdi and villages like Moshi, Chikli, Dehu, etc. The private teaching hospital is a 900 bedded hospital with hi-tech super specialties. It is located in inner suburbs of Pune which includes areas like Katraj, Ambegaon, Vadgaon, Parvati Hill, etc. These are the industrial and agricultural areas where high number of chemical or pesticide poisoning can be observed.

\section{Population and Sampling}

The study was cross-sectional and made use of retrospective extraction of data from records available at the government and private teaching hospitals respectively. All cases of poisoning available in the medical record departments were included in the study.

\section{Data Collection and Extraction:}

The records were collected from Medical Record Department of the respective hospitals. The data collection period was from January 2013 to December 2015. The cases were reviewed for gender, age, route and reason of poisoning, seasonal variation and agents. Poisonous agents were described and grouped in accordance with International Classification of Diseases [ICD-10].

Statistical Analysis: Data was collected in predefined forms. Chi Square test was used to determine the association between the variables. $\mathrm{P}<0.05$ was used to determine significance.

\section{RESULTS}

\section{Demography of poisoning cases and toxic agents involved}

A total of 1010 cases were reviewed over a span of 3 years. Marital status and occupational background were not included in the study due to inappropriateness and unavailability of data in many case files. The sex, age, reason of poisoning, route of poisoning, seasonal variation and agents involved in poisoning is according to the records available. Thirteen cases were reported dead on admission. The post mortem reports of these cases were reviewed for sex, reason and route of poisoning, and agents but age was unavailable. The age of patients ranged from $0-72$ years with a median age of 27 years. Poisoning in males was predominant $(56.24 \%)$ with a male to female ratio of 1.3:1. Maximum number of cases was observed in the age group of 20-35 years (55.5\%) followed by 13-19 years $(14.9 \%)$. Increased female cases were reported in age category $13-19$ years (65.3\%) (Table 2). Poisoning was more during summer season (35.1\%). Household and agricultural agents (56.4\%) followed by bites and stings (26.4\%) were associated with most poisoning (Table 1). Organophosphates and carbamates were the most common causes. Drug poisoning was reported in $10.8 \%$ cases and maximum abuse was by NSAIDs and antipyretic agents. Drugs were widely used by children of 13-19 yrs as self-harm (Table 2)

\section{Reason and Route of poisoning}

Intentional poisoning was more common (53.3\%) and maximum in $20-35$ age category $(65.2 \%)[\mathrm{p}<0.05]$. Household and agricultural agents (79.4\%) were used widely and drugs (16.7\%) were the second most used agent for intentional poisoning $[\mathrm{p}<0.05]$. Most cases in age group 13-19 years were intentional $(16.5 \%)$ [ $<<0.05]$. Accidental cases were maximum in $20-35$ yrs $(39.8 \%)$ followed by $24.4 \%$ in age group $0-12$ years. $60.4 \%$ percent accidental poisoning was due to bites and stings (Table 3). Animal bites and stings were the most common cause of accidental poisoning. In people above 55 years, accidental were more compared to intentional, the reason being old age, mishandling and non adherence. Out of all
Table 1: Characteristics of Poisoning Cases Reviewed

\begin{tabular}{|c|c|c|}
\hline Characteristics & Frequency & Proportion (\%) \\
\hline \multicolumn{3}{|l|}{ Sex } \\
\hline Male & 568 & 56.24 \\
\hline Female & 442 & 43.76 \\
\hline \multicolumn{3}{|l|}{ Age } \\
\hline $0-12$ & 108 & 10.7 \\
\hline $13-19$ & 150 & 14.9 \\
\hline $20-35$ & 560 & 55.5 \\
\hline $36-55$ & 140 & 13.9 \\
\hline$>55$ & 39 & 3.9 \\
\hline \multicolumn{3}{|l|}{ Reason for poisoning } \\
\hline Intentional & 539 & 53.3 \\
\hline Accidental & 442 & 43.8 \\
\hline Unknown & 29 & 2.9 \\
\hline \multicolumn{3}{|l|}{ Route of Poisoning } \\
\hline Ingestion & 702 & 69.5 \\
\hline Injection & 1 & 0.1 \\
\hline Inhalational & 39 & 3.9 \\
\hline Bite/Sting & 267 & 26.4 \\
\hline Eye & 1 & 0.1 \\
\hline \multicolumn{3}{|l|}{ Season of Poisoning } \\
\hline Summer & 355 & 35.1 \\
\hline Monsoon & 322 & 31.9 \\
\hline Winter & 333 & 33.0 \\
\hline \multicolumn{3}{|l|}{ Agent Involved } \\
\hline Household and Agricultural products & 570 & 56.4 \\
\hline Animal Bites and Stings & 267 & 26.4 \\
\hline Drugs & 109 & 10.8 \\
\hline Plants and Miscellaneous & 36 & 3.6 \\
\hline Unspecified & 28 & 2.8 \\
\hline
\end{tabular}

- Marital status and occupational background were not included due to unavailability of data.

- 13 cases were reviewed from post mortem reports where age was not available.

cases reported, oral ingestion was the most common route of exposure (69.6\%) followed by bites and stings (26.4\%), inhalational (3.9\%) and injection $(0.1 \%)$. The reported 39 exposures by inhalational were accidental occupational exposure whereas one exposure by injection was accidental higher dose of Insulin in a 40 year old female.

\section{Outcome of Poisoning with Time of exposure, Time of Hospitalization and Time lag}

Maximum patients (77.6\%) responded to the therapy given while $12.6 \%$ absconded, took Discharge against Medical Advice (DAMA) or were 
Table 2: Patient Characteristics According to Age Category

\begin{tabular}{|c|c|c|c|c|c|c|}
\hline \multirow[t]{2}{*}{ Characteristics } & \multicolumn{6}{|c|}{ Age in years [Numbers (\%)] } \\
\hline & $0-12[n=108]$ & $13-19[n=150]$ & $20-35[n=560]$ & $36-55[n=140]$ & $>55[n=39]$ & $P$ value \\
\hline Sex & & & & & & $<0.05$ \\
\hline Female & $41(38.0)$ & $98(65.3)$ & $236(42.1)$ & $53(37.9)$ & $9(23.1)$ & \\
\hline Reason for poisoning & & & & & & $<0.05$ \\
\hline Unknown & $0(0)$ & $7(4.7)$ & $19(3.4)$ & $2(1.4)$ & $1(2.5)$ & \\
\hline Route of Poisoning & & & & & & $<0.05$ \\
\hline Ingestion & $45(41.7)$ & $135(90.0)$ & $439(78.4)$ & $49(35.0)$ & $21(53.8)$ & \\
\hline Inhalational & 0 & $2(1.3)$ & $3(0.5)$ & $34(24.3)$ & 0 & \\
\hline Agents Involved & & & & & & $<0.05$ \\
\hline Household and Agricultural products & $21(19.5)$ & $115(76.7)$ & $345(61.6)$ & $61(43.6)$ & $17(43.6)$ & \\
\hline Animal Bites and Stings & $63(58.3)$ & $13(8.6)$ & $116(20.7)$ & $58(41.4)$ & $15(38.5)$ & \\
\hline Drugs & $5(4.6)$ & $16(10.7)$ & $68(12.1)$ & $16(11.4)$ & $4(10.3)$ & \\
\hline Plants and Miscellaneous & $17(15.7)$ & $3(2.0)$ & $11(2.0)$ & $3(2.1)$ & $2(5.1)$ & \\
\hline Unspecified & 2(1.9) & $3(2.0)$ & $20(3.6)$ & $2(1.4)$ & $1(2.6)$ & \\
\hline
\end{tabular}

13 cases were reviewed from post mortem reports where age was not available.

- $\quad$ p value was calculated using Chi-square test.

Table 3: Factors Associated with Reason for Poisoning

\begin{tabular}{|c|c|c|c|c|}
\hline \multirow[t]{2}{*}{ Characteristics } & \multicolumn{3}{|c|}{ Reason for poisoning [Numbers (\%)] } & \multirow[b]{2}{*}{$P$ value } \\
\hline & Accidental [N=442] & Intentional [N=539] & Unknown [N=29] & \\
\hline Sex & & & & $<0.05$ \\
\hline Male & $281(63.6)$ & $270(50.1)$ & $17(58.6)$ & \\
\hline Female & $161(36.4)$ & $269(49.9)$ & $12(41.4)$ & \\
\hline Age & & & & $<0.05$ \\
\hline $0-12$ & $108(24.4)$ & 0 & 0 & \\
\hline $13-19$ & $54(12.2)$ & $89(16.5)$ & $7(24.1)$ & \\
\hline $20-35$ & $176(39.8)$ & $365(67.7)$ & $19(65.5)$ & \\
\hline $36-55$ & $76(17.2)$ & $62(11.5)$ & $2(6.9)$ & \\
\hline$>55$ & $26(5.9)$ & $12(2.2)$ & $1(3.5)$ & \\
\hline Route of Poisoning & & & & $<0.05$ \\
\hline Ingestion & $134(30.3)$ & $539(100)$ & $29(100)$ & \\
\hline Inhalational & $39(8.8)$ & 0 & 0 & \\
\hline Bite/Sting & $267(60.4)$ & 0 & 0 & \\
\hline Injection & $1(0.2)$ & 0 & 0 & \\
\hline Eye & $1(0.2)$ & 0 & 0 & \\
\hline Agent Involved & & & & $<0.05$ \\
\hline Household and Agricultural products & $117(26.5)$ & $428(79.4)$ & $25(86.2)$ & \\
\hline Animal Bites and Stings & $267(60.4)$ & 0 & 0 & \\
\hline Drugs & $16(3.6)$ & $90(16.7)$ & $3(10.3)$ & \\
\hline Plants and Miscellaneous & $36(8.1)$ & 0 & 0 & \\
\hline Unspecified & $6(1.4)$ & 21(3.9) & $1(3.5)$ & \\
\hline
\end{tabular}

$P$ value was calculated using Chi-square test. 
Table 4: Factors Associated with Outcome of Poisoning

\begin{tabular}{|c|c|c|c|c|}
\hline \multirow[t]{2}{*}{ Characteristics } & \multicolumn{4}{|c|}{ Outcome for poisoning [Numbers (\%)] } \\
\hline & $\begin{array}{c}\text { Recovered } \\
{[\mathrm{N}=784]}\end{array}$ & $\begin{array}{l}\text { DAMA/Absconded/ } \\
\text { Referral [N=127] }\end{array}$ & Death [N=99] & $P$ value \\
\hline Sex & & & & $<0.05$ \\
\hline Male & $420(53.6)$ & $82(64.6)$ & $70(70.7)$ & \\
\hline Female & $364(46.4)$ & $45(35.4)$ & $29(29.3)$ & \\
\hline Age & & & & $<0.05$ \\
\hline $0-12$ & $89(11.2)$ & $7(5.5)$ & $12(12.1)$ & \\
\hline $13-19$ & $122(15.4)$ & $25(18.9)$ & $3(3.0)$ & \\
\hline $20-35$ & $452(57.9)$ & 77 (63.8) & $31(44.4)$ & \\
\hline $36-55$ & $101(12.9)$ & $13(8.7)$ & $26(26.3)$ & \\
\hline$>55$ & $21(2.6)$ & $4(3.1)$ & $14(14.2)$ & \\
\hline Route of Poisoning & & & & $<0.05$ \\
\hline Ingestion & $513(65.4)$ & $109(85.8)$ & $80(80.8)$ & \\
\hline Inhalational & $35(4.5)$ & 0 & $4(4.1)$ & \\
\hline Bite/Sting & $235(30.0)$ & $18(14.2)$ & $14(14.1)$ & \\
\hline Injection & 0 & 0 & $1(1.0)$ & \\
\hline Eye & $1(0.1)$ & 0 & 0 & \\
\hline Agent Involved & & & & $<0.05$ \\
\hline Household and Agricultural products & $410(52.3)$ & $78(61.4)$ & $82(82.8)$ & \\
\hline Animal Bites and Stings & $225(28.7)$ & $28(22.1)$ & $14(14.2)$ & \\
\hline Drugs & $93(11.9)$ & $14(11.0)$ & $2(2.0)$ & \\
\hline Plants and Miscellaneous & $34(4.3)$ & $2(1.6)$ & 0 & \\
\hline Unspecified & $22(2.8)$ & $5(3.9)$ & $1(1.0)$ & \\
\hline
\end{tabular}

- $\quad$ p value was calculated using Chi-Square Test

referred to another hospital $[\mathrm{p}<0.05]$. Symptoms improved in $74.5 \%$ cases and did not improve in $9.8 \%$. The mortality found in the present study was $9.8 \%$ with predominance of males to females in death cases. According to available data, most death was seen in adults (Table 4). Maximum death were reported due to exposure to household and agricultural agents (82.8\%) followed by animal bites and stings (14.1\%) and drug poisoning (2.0\%) (Table 4$)$. Mortality due to organophosphates was highest (55.6\%) (Figure 1). An increased trend in consumption of alcohol along with toxic agent for self harm was observed, increasing the risk of aspiration, coma and respiratory failure leading to death. Exact Time of Exposure (TOE) was unavailable in majority of the cases. According to available data, TOE was maximum during $6 \mathrm{pm}-12$ am followed by daytime between $6 \mathrm{am}-12 \mathrm{pm}$ (Figure 2). Time of Hospitalization (TOH) was available in majority cases and was found highest during afternoon $12 \mathrm{pm}-6$ am and maximum death was also recorded during this time (Figure 3). The time lag between TOE and TOH was determined by the available data. Maximum time lag of 1-3 $\mathrm{h}$ was found in the study. One case with time lag more than $24 \mathrm{~h}$ died whereas cases with time lag less than $1 \mathrm{~h}$ showed better recovery (Figure 4).

\section{DISCUSSION}

A wide range of age groups of both genders were found exposed and victims to poisoning, with male predominance. A similar trend was reported by studies conducted in Northern, ${ }^{3,4,6}$ Southern, ${ }^{8,9}$ Western ${ }^{12,13,15}$ and Eastern ${ }^{16}$ regions of India and countries like Sri Lanka ${ }^{17}$ and Uganda. ${ }^{18}$ This trend may be due to increased occupational hazard and exposure of men to stress as they are the only earning members of a large family.,19 The high incidence of poisoning in age group 20-35 years may be due to domestic, educational and employment related stress. Also the easy availability of household agents thereby explains the preponderance. Domestic violence, emotional status of young girls and their vulnerability to stress during puberty is the reason for increased female cases in age category 13-19 yrs. Rapid increase of indebtedness by farmers and failure to reimburse due to natural calamities like draught is the reason behind the increase in poisoning during summer season. ${ }^{10,11}$ India being an agriculture nation, handling of pesticides is a routine practice by farmers and their family members. Household and agricultural agents (56.4\%) were associated with most poisoning due to easy availability of these agents and inadequate knowledge to support their safe residential use. ${ }^{20}$ Studies have shown that pesticide is the most common toxic agent involved in poisoning. ${ }^{21,22}$ Drug poisoning was reported in $10.8 \%$ cases and maximum abuse was by NSAIDs and antipyretic agents, which were also the case in United States according to Centres for Disease Control and Prevention ${ }^{23}$ followed by anti psychotic drugs, anti parasites and anti infective agents, anti epileptics, these drugs were also abused by children of 13-19 yrs as self-harm. This may be due to availability of drugs consumed by elders at home. 


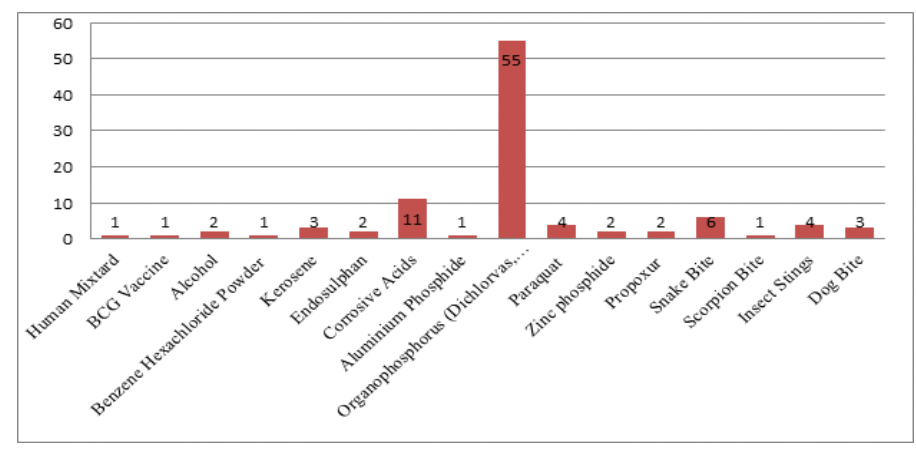

Figure 1: Agents Responsible for Mortality

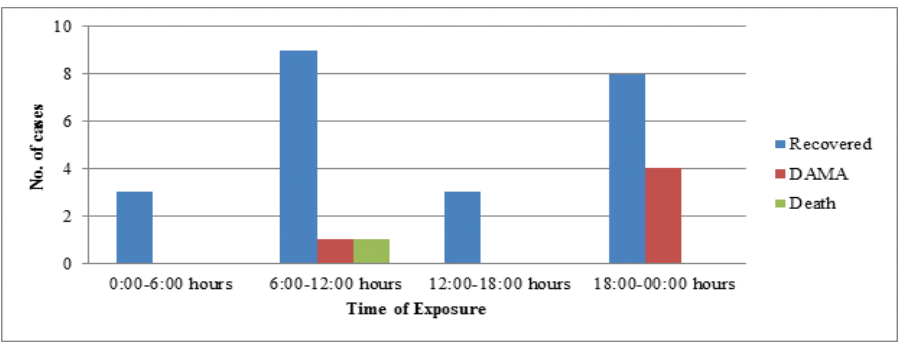

Figure 2: Outcome of Poisoning in accordance to Time of Exposure

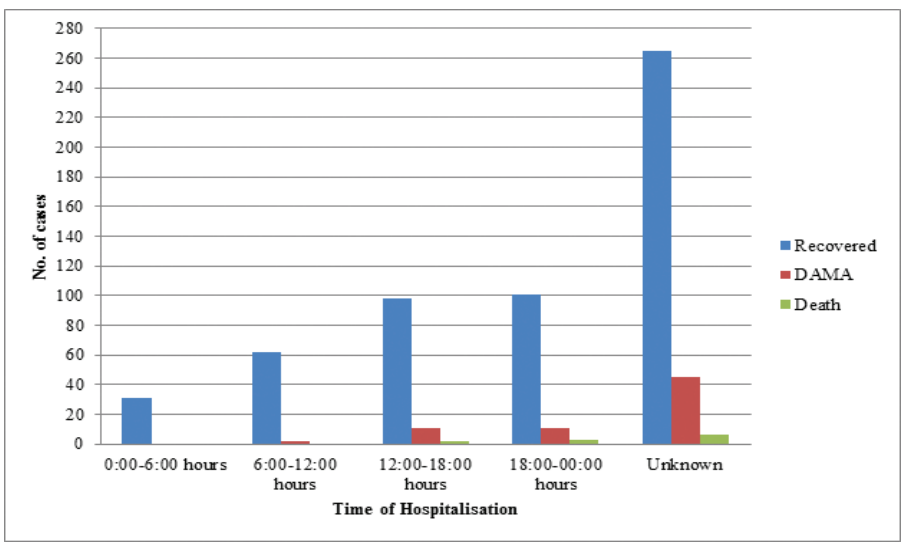

Figure 3: Outcome of Poisoning in accordance to Time of Hospitalisation

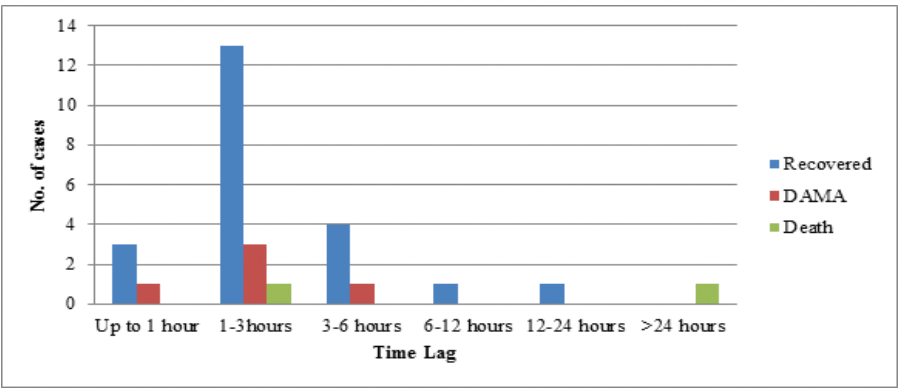

Figure 4: Outcome of Poisoning in accordance to Time Lag
Intentional poisoning was more common which was similar to other studies mentioned above. Maximum exposure in 20-35 age category is due to family dispute, domestic violence, and stress due to job/unemployment. Household and agricultural agents were used widely. The reason behind this is easy availability of these agents in common household and agricultural use. Intentional poisoning cases more prevalent in age group 13-19 yrs may be due to increasing suicidal tendencies in teens due to peer pressure, unwarranted expectations by parents to perform well in studies, and family issues. Animal bites and stings were the most common cause of accidental poisoning which was contrary to findings of the studies conducted in South India where most accidental poisoning was due to household poisons. ${ }^{24,25}$ This may be due to the difference in geography and occupation. Old age, mishandling and non adherence of medicinal drugs in people above $55 \mathrm{yrs}$ is the possible cause for accidental poisoning. The most likely explanation behind absconding is due to low socioeconomic status of the patient and to refrain from medico-legal proceedings. The reason behind referral to other hospitals is due to lack of specialty treatment in the hospital. DAMA may be due to lack of awareness and improper counselling to the patients. The mortality found in the present study $9.8 \%$, is higher compared to Eastern and Southern regions where it was $3.84 \%{ }^{16}$ and $7.5 \%{ }^{7}$ respectively and lower than Northern regions ${ }^{26}$ other Western regions. ${ }^{14}$ Predominance of males was found compared to females in death cases and similar pattern was observed in other study. ${ }^{27}$ According to available data, most death was seen in adults which was similar to reports by Poison Statistics National Data 2014 that poisonings in Teens and Adults are more serious. ${ }^{28}$

Mortality due to organophosphates was highest according to the present study which was similar to the study conducted in South India. Aluminium phosphide is observed as the leading cause of poisoning in South India. An increased trend in consumption of alcohol along with toxic agent for self harm was observed, increasing the risk of aspiration, coma and respiratory failure leading to death. Maximum exposure during $6 \mathrm{pm}$ - 12 am might be that people tend to over think about their problems more in the evening. Unable to cope up with the stress, they tend to take extreme measures and harm themselves.

\section{CONCLUSION}

Increased intentional poisoning in teens and adults emphasize on importance of counseling and awareness about depression and stress affecting the major strata of the society which increases suicidal tendencies. Awareness and education among the population about safety from hazardous chemicals at household and occupational level is a strong indication to prevent accidental poisoning. Maximum cases reported with time lag of 1-3 h suggests the need for awareness about first aid in emergency situation at primary healthcare level. Burden of poisoning and animal bite cases brought to casualty demands strategies for identification and rational management providing optimal outcomes.

The study was conducted retrospectively by collecting the data from medical records, which missed out vital information about socio-economic details of the patients. Poor maintenance of records was frequently observed in the government setting. Cases referred from other hospitals lacked detailed patient history. The time of exposure and admission were not recorded in all the files.

\section{ACKNOWLEDGEMENT}

None.

\section{CONFLICT OF INTEREST}

None. 


\section{REFERENCES}

1. World Health Organization. Poisoning Prevention and Management. http:// www.who.int/ipcs/poisons/en/ (accessed 18 August 2016).

2. All India Institute of Medical Sciences, New Delhi. National Poisons Information Centre. http://www.aiims.edu/en/departments-and-centers/central-facilities. html?id=167 (accessed 18 August 2016)

3. Mittal N, Shafiq N, Malhotra S, Bhalla A, Pandhi P. A prospective observational study on different poisoning cases and their outcomes in a tertiary care hospital. SAGE Open Medicine. 2013:1:1-5. https://doi.org/10.1177/2050312113504213; PMid:26770682 PMCid:PMC4687764.

4. Zaheer MS, Aslam M, Gupta V, Sharma V, Khan SA. Profile of poisoning cases at a North Indian tertiary care hospital. Health and Population: Perspectives and Issues. 2009;32(4):167-83

5. Gargi J, Tejpal HR, Chanana A, Rai G, Chaudhary R. A retrospective autopsy study of poisoning in the northern region of Punjab. Journal of Punjab Academic Forensic and Medical Toxicology. 2008;8(2):17-9.

6. Gupta P, Kumar A, Singh SP, Prakash M, Gupta M, Kumar P. Pattern of Cases of Acute Poisoning in a Rural Tertiary Care Center in Northern India. Nationa Journal of Community Medicine. 2016;7(4):307-10.

7. Shetty BSK, Kanchan T, Menezea RG, Shetty M, Arun M, Salian PRV et al. Poisoning fatalities in Mangalore, South India: A three year snapshot. International Journal of A J Institute of Medical Sciences. 2012;1(2):104-111.

8. Ramesh V, Chavan VR, Arshad M, Raghunandan M, Faizuddin. A Study on Pattern of Acute Poisoning in an Emergency Department of a Tertiary Care Hospital. Asian Journal of Pharmaceutical and Clinical Research. 2016;9(3):361-3.

9. Kanchan T, Menezes RG, Kumar TS, et al. Toxicoepidemiology of fatal poisonings in Southern India. Journal of Forensic and Legal Medicine. 2010;17:344-7. https://doi.org/10.1016/j.jflm.2010.05.006 ; PMid:20650426

10. Naresh DTV, Shailendra D, Subbaratnam Y, Prasuna G, Rajashekar K, Mary Rohini. Profile of Poisoning Cases in Tertiary Care Hospital, Telangana, India. Journal of Evidence based Medicine and Healthcare. 2015;2(20):3032-8. https://doi. org/10.18410/jebmh/2015/439.

11. Maharani B, Vijayakumari N. Profile of poisoning cases in a Tertiary care Hospital, Tamil Nadu, India. Journal of Applied Pharmaceutical Science. 2013;3(1)91-4. https://doi.org/10.7324/japs.2013.30117.

12. Vaidya UP, Hulke SM. Study of trends of poisoning in cases reported to government hospitals, Yavatmal. Chronicles of Young Scientists India 2012;3(1):63-7. https://doi.org/10.4103/2229-5186.94321.

13. Kumar S, Sheikh M, Gupta S. Comparative study and changing trends of poisoning in year 2004-2005 at Surat, India. International Journal of Medical Toxicology and Legal Medicine. 2007;10(1):16-20.

14. Somasundaram KV, Patil A, Shukla SK. Epidemiological Profile of OP Poisoning Cases Treated at Pravara Hospital, Loni, India. Indian Journal of Preventive and Social Medicine 2009;40(3):184-8.

15. Raut, Pavankumar K, Tingne, Chaitanya, Gajbhiye et al. Socio-Demographic Study of Poisoning Cases at I.G.G.M.C. Nagpur [abst]. Indian Journal of Forensic Medicine \& Toxicology. 2016;10(1):189-93. https://doi.org/10.5958/ 0973-9130.2016.00043.8.

16. Panda BB, Hansda MK, Mishra K, Samantsinghar P. Study of Poisoning Cases in an Indian Tertiary Care Teaching Hospital. Journal of Indian Academy of Forensic Medicine. 2015;37(2):165-8. https://doi.org/10.5958/0974-0848.2015.00040.8.

17. Hoek VW, Konradsen F. Analysis of 8000 hospital admissions for acute poisoning in a rural area of Sri Lanka. Clinical Toxicology. (Philadelphia, Pa.) 2006;44(3):225-31. https://doi.org/10.1080/15563650600584246.

18. Malangu N. Acute Poisoning at two hospitals in Kampala - Uganda. Journal of Forensic and Legal Medicine. 2008;15(8):489-92. https://doi.org/10.1016/j. jflm.2008.04.003; PMid:18926499.

19. Z'gambo J, SiulapwaY, Michelo C. Pattern of acute poisoning at two urban referral hospitals in Lusaka, Zambia. BMC Emergency Medicine. 2016;16(1):2. https:// doi.org/10.1186/s12873-016-0068-3 ; PMid:26748777 PMCid:PMC4706701.

20. John NA, John J. Prolonged use of mosquito coil, mats, and liquidators: A review of its health implications. International Journal of Clinical and Experimental Physiology. 2015;2(4):209-13. https://doi.org/10.4103/2348-8093.175390.

21. Kumar SV, Venkateswarlu B, Sasikala M, Kumar GV. A study on poisoning cases in a tertiary care hospital. Journal of Natural Science, Biology and Medicine. 2010;1(1):35-9. https://doi.org/10.4103/0976-9668.71671; PMid:22096334 PMCid:PMC3217281.

22. Banerjee I, Tripathi SK, Sinha R, Sengupta P. Pesticide use pattern among farmers in a rural district of West Bengal, India. Journal of Natural Science, Biology and Medicine. 2014;15(2):313-6. https://doi.org/10.4103/0976-9668.136173; PMid:25097405 PMCid:PMC4121905

23. Centres for Disease Control and Prevention. QuickStats: Number of Deaths From Poisoning,* Drug Poisoning, $\dagger$ and Drug Poisoning Involving Opioid Analgesics§ — United States, 1999-2010. https://www.cdc.gov/mmwr/preview/ mmwrhtml/mm6212a7.htm (accessed 26 september 2016).

24. Jesslin J, Adepu R, Churi S. Assesment of Prevelence and Mortality Incidence due to poisoning in South Indian Tertiary Care Teaching Hospital. Indian Journal of Pharmaceutical Sciences. 2010;72(5):587-91. https://doi.org/10.4103/0250474X.78525; PMid:21694990 PMCid:PMC3116303.

25. Shakuntala, Yogesh G. Analysis of Organophosphorus Poisoning, at tertiary care Hospital: A Report. Journal of Evidence based Medicine and Healthcare. 2015;2(4):421-30. https://doi.org/10.18410/jebmh/2015/59.

26. Gupta B, Kishore K, Rastogi P, Singh R. Retrospective Study of Poisoning Cases at Tertiary Care Hospital in Western Uttar Pradesh. Journal of Indian Academy of Forensic Medicine. 2016;38(1):11-14. https://doi.org/10.5958/09740848.2016.00002.6.

27. Nishtar S, Bile KM, Ahmed A, Amjad S, Iqbal A. Integrated population-based surveillance of noncommunicable diseases: the Pakistan model. American Journal of Preventive Medicine. 2005;29(Suppl1):102-6. https://doi.org/10.1016/j.amepre. 2005.07.034; PMid:16389134

28. National Capital Poison Centre. Poison Statistics National Data 2014. http:// www.poison.org/poison-statistics-national (accessed 22 February 2016).

Article History: Submission Date : 16-11-2016; Revised Date : 11-02-2017; Acceptance Date : 07-03-2017.

Cite this article: Asawari R, Atmaram P, Bhagwan K, Priti D, Kavya S, Jabeen GA. Toxicological Pattern of Poisoning in Urban Hospitals of Western India. JYoung Pharm. 2017:9(3):315-20. 